\title{
Systematic evaluation of errors occurring during the preparation of intravenous medication
}

\author{
Christopher S. Parshuram MB ChB DPhil, Teresa To PhD, Winnie Seto BScPhm PharmD, \\ Angela Trope MSc RPh, Gideon Koren MBBS, Andreas Laupacis MD MSc
}

$\infty$

See related article page $6_{3}$

\section{ABSTRACT}

Introduction: Errors in the concentration of intravenous medications are not uncommon. We evaluated steps in the infusion-preparation process to identify factors associated with preventable medication errors.

Methods: We included 118 health care professionals who would be involved in the preparation of intravenous medication infusions as part of their regular clinical activities. Participants performed 5 infusion-preparation tasks (drug-volume calculation, rounding, volume measurement, dose-volume calculation, mixing) and prepared 4 morphine infusions to specified concentrations. The primary outcome was the occurrence of error (deviation of $>5 \%$ for volume measurement and $>10 \%$ for other measures). The secondary outcome was the magnitude of error.

Results: Participants performed 1180 drug-volume calculations, 1180 rounding calculations and made $176_{7}$ syringe-volume measurements, and they prepared 464 morphine infusions. We detected errors in $58(4.9 \%, 95 \%$ confidence interval [Cl] $3.7 \%$ to $6.2 \%)$ drug-volume calculations, $30(2.5 \%, 95 \% \mathrm{Cl}$ $1.6 \%$ to $3.4 \%$ ) rounding calculations and $29(1.6 \%, 95 \% \mathrm{Cl} 1.1 \%$ to $2.2 \%$ ) volume measurements. We found 7 errors ( $1.6 \%$, $95 \%$ $\mathrm{Cl} 0.4 \%$ to $2.7 \%$ ) in drug mixing. Of the 464 infusion preparations, $161(34.7 \%, 95 \% \mathrm{Cl} 30.4 \%$ to $39 \%$ ) contained concentration errors. Calculator use was associated with fewer errors in dose-volume calculations ( $4 \%$ v. $10 \%, p=0.001$ ). Four factors were positively associated with the occurence of a concentration error: fewer infusions prepared in the previous week ( $p=$ 0.007 ), increased number of years of professional experience $(p=0.01)$, the use of the more concentrated stock solution $(p<$ $0.001)$ and the preparation of smaller dose volumes $(p<0.001)$. Larger magnitude errors were associated with fewer hours of sleep in the previous 24 hours $(p=0.02)$, the use of more concentrated solutions $(p<0.001)$ and preparation of smaller infusion doses $(p<0.001)$.

Interpretation: Our data suggest that the reduction of provider fatigue and production of pediatric-strength solutions or industry-prepared infusions may reduce medication errors.

Une version française de ce résumé est disponible à l'adresse www.cmaj.ca/cgi/content/full/I78/I/42/DCI

CMAJ 2008;178(I):42-8
M edication errors are a major cause of preventable patient harm. ${ }^{1-7}$ Generic practices to prevent these errors include pharmacy centralization, ${ }^{8,9}$ specialization of practitioners, ${ }^{10,11}$ standardization of drug concentrations ${ }^{9}$ and reduction of fatigue of health care workers. $^{12,13}$ These practices have been legislated and applied based on empirical ideas in the absence of high-grade evidence. ${ }^{9}$

Current pharmaceutical regulations require that intravenously delivered medications be within 10\% of the stated concentration. ${ }^{14}$ More stringent requirements are in place in some jurisdictions. ${ }^{15}$ Direct assessment of intravenous drug infusions received by patients has suggested that up to $65 \%$ of infusions have unacceptable concentrations by industry standards despite routine safety practises. ${ }^{16-23}$ We performed a systematic evaluation of the preparation process for intravenous infusions to identify factors associated with preventable medication errors.

\section{Methods}

\section{Study design}

We performed a direct observational study in a structured, nonclinical environment. We included qualified health care professionals (physicians, registered nurses, pharmacists and pharmacy technicians) who would be involved in the preparation of intravenous drug infusions. Participants were recruited from March 2003 to February 2004 by informal contact and self-identification to the study team. After completing a survey to describe their individual characteristics, participants were asked to perform Io drug-volume calculations $;^{24}$ to round Io numbers to match specified syringe graduations; to draw 5 volumes of water into each of $\mathrm{I}-\mathrm{mL}, 3-\mathrm{mL}$ and 6o-mL syringes; and to prepare 4 infusions of morphine sulfate at the following concentrations: 0.6 ( 2 infusions), 2.4 and $7.3 \mathrm{mg} / 50 \mathrm{~mL}$. The 2 infusions of $0.6 \mathrm{mg} / 50 \mathrm{~mL}$ were pre-

From the Department of Critical Care Medicine (Parshuram), the Department of Pharmacy (Seto, Trope), the Center for Safety Research, Child Health Evaluative Sciences Program (Parshuram, To, Seto, Trope, Koren), the Research Institute, The Hospital for Sick Children; the Departments of Paediatrics (Koren), and Health Policy Management and Evaluation (To, Laupacis), University of Toronto; and the Institute for Clinical and Evaluative Sciences (Laupacis), Toronto, Ont. 
pared from different commercially available stock solutions ( $2 \mathrm{mg} / \mathrm{ml}$, Io $\mathrm{mg} / \mathrm{mL}$ ). Both of the other morphine infusions were prepared from a $10-\mathrm{mg} / \mathrm{mL}$ stock solution. Calculators were readily available to participants, and we document calculator use for each calculation. After preparing the infusions, participants were asked to rate the accuracy of solutions they had prepared.

A registered nurse administered the survey to the participants and read the instructions aloud for the infusionpreparation tasks and for preparation of the morphine infusions. A second observer ensured that the instructions were read clearly and correctly to the participant, and this observer independently verified the measurements. Differences were resolved by consensus. Water was weighed with an accurate balance that was calibrated monthly. The study environment temperature was $20^{\circ} \mathrm{C}-22^{\circ} \mathrm{C}$. Correction for the density of water was not performed. We collected 2 samples (I mL each) from the first and last $5 \mathrm{~mL}$ of each prepared morphine infusion, and the samples were stored at $-20^{\circ} \mathrm{C}$ in glass vials. Morphine is stable under these conditions. ${ }^{25-27}$

We measured the concentrations of the prepared morphine infusions using a high-performance liquid chromatography assay. ${ }^{28}$ A 6-point standard curve was constructed over the interval $0-0.5 \mathrm{mg} / \mathrm{mL}$. During the course of the study, 3 separate batches were processed $\left(r^{2} \geq 0.9998\right.$, $p<0.00 I)$. We adjusted for differences in molecular weights of morphine sulfate used to calculate the standard curve in the laboratory and the pentahydrate form used in the commercial preparations. ${ }^{17}$

To support the analysis of Io variables and the subgroup analyses, we chose a sample size of 120 participants. ${ }^{29}$ The study was approved by the research ethics board at The Hospital for Sick Children. All participants provided written consent.

\section{Outcomes}

The primary outcome was the occurrence of errors. An error was considered to have occurred if a participant's response or prepared morphine infusion was outside industry standards. ${ }^{14,30,31}$ For measures with no industry standard, we used accepted standards for intravenous medications (within 10\% of the expected concentration). Thus, we defined errors for drug calculations, rounding, mixing and infusion concentrations as a deviation of 10\% or greater from the expected value. ${ }^{14}$ We defined volumetric error as a deviation of $5 \%$ or greater from the expected volume. ${ }^{30,31}$ Secondary outcomes were the number and magnitude of errors.

\section{Data analysis}

We entered the data in duplicate into a Microsoft Access 2000 database. Percentage error was calculated as follows: percentage error $=$ (measured concentration - ideal concentration) $\times$ Ioo/(ideal concentration). ${ }^{17}$ Percentage error introduced during the mixing phase of preparation was determined as follows: percentage error $=$ (measured concentration in the first $5 \mathrm{~mL}$ of the syringe - measured concentration in the last $5 \mathrm{~mL}$ of the syringe) $\times$ Ioo/(mean concentration in syringe). This modification removed the effect of any errors in the total amount of drug in the syringe; thus, we could independently assess errors introduced by mixing. In both formulas, a positive percentage error indicated measurements or responses that were greater than expected, and a negative percentage error indicated measurements or responses that were less than expected.

We classified prepared morphine infusions as having 2 -fold errors if the concentration was more than double or less than half the expected concentration. The magnitude of error was represented categorically by the number of 2 -fold errors. Log-transformation of these data was used to counter the skewed distribution that resulted from the use of percentage error as a continuous measure.

We used the $\chi^{2}$ test to compare individual characteristics (profession, years of experience, number of infusions prepared in the previous week, number of hours of sleep in the previous 24 hours) with the rate of errors. We calculated a correlation matrix of the number of errors made by participants for each infusion-preparation task.

We used analysis of variance to assess the relation between professional background and magnitude of error in infusion-preparation tasks. We used multiple regression analyses to evaluate the frequency and magnitude of errors in the prepared morphine infusions. First, we used linear regression analysis to analyze the number of infusions with errors. Second, we used repeated-measures regression analysis to compare the number of errors and error magnitude (absolute log-transformed error) with io explanatory variables (medication dose, stock-solution concentration, drugvolume calcuation, rounding, volume measurment, mixing, fatigue, recent infusion preparation experience, professional background and years of professional experience) (Figure I). In all regression analyses, the explanatory variables were represented as continuous values (except professional background). The least significant variable was eliminated in a backward stepwise process, until only variables significant at the 0.05 level remained.

\section{Results}

A total of II8 people agreed to participate. The largest proportion of participants were registered nurses (Table I). Most participants had prepared I or more infusions in the previous week. In total, participants performed ir8o drug-volume calculations and II80 rounding calculations. Participants also made 1767 syringe-volume measurements and prepared 464 morphine infusions. For 13 infusion preparations, I of the 2 mixing samples was damaged during storage; thus, mixing error was assessed for $45 \mathrm{I}$ (97.2\%) of the infusions.

\section{Accuracy of infusion-preparation tasks}

We found errors in $58(4.9 \%, 95 \%$ confidence interval [CI] $3.7 \%$ to $6.2 \%)$ drug-volume calculations, $30(2.5 \%, 95 \% \mathrm{CI}$ I. $6 \%$ to $3.4 \%$ ) rounding calculations and 29 (1.6\%, $95 \% \mathrm{CI}$ I.I \% to $2.2 \%$ ) volume measurements. We found 7 errors (I.6\%, $95 \%$ CI $0.4 \%$ to $2.7 \%$ ) in the mixing of prepared infusions. Participants who had more than ro years of professional experience were more likely than those with less experience to make I or more errors in rounding calculations 
( $p=0.003)$. There was no other significant relation between errors and professional characteristics for any of the infusion-preparation tasks. The number of errors made by each participant in each infusion-preparation task was not associated with the number of errors he or she made in any other task $(r=-0.09$ to 0.12 , all $p>0.30)$. The magnitude of errors was not associated with professional characteristics (Table 2).
Of the 58 errors in drug-volume calculations, $4 \mathrm{I}$ (3.5\%) were 2-fold or greater, and I4 (I.2\%) were Io-fold errors (either Io times greater or Io times less than the correct answer). Participants used calculators for 973 (82.5\%) of the calculations. Calculator use was associated with fewer calculation errors (3.8\% v. IO.I\%, $p<0.00 \mathrm{I})$. The reduction in 2-fold errors with calculator use was not significant $(3.1 \% \mathrm{v}$. $5.3 \%, p=0 . \mathrm{II}$ ).

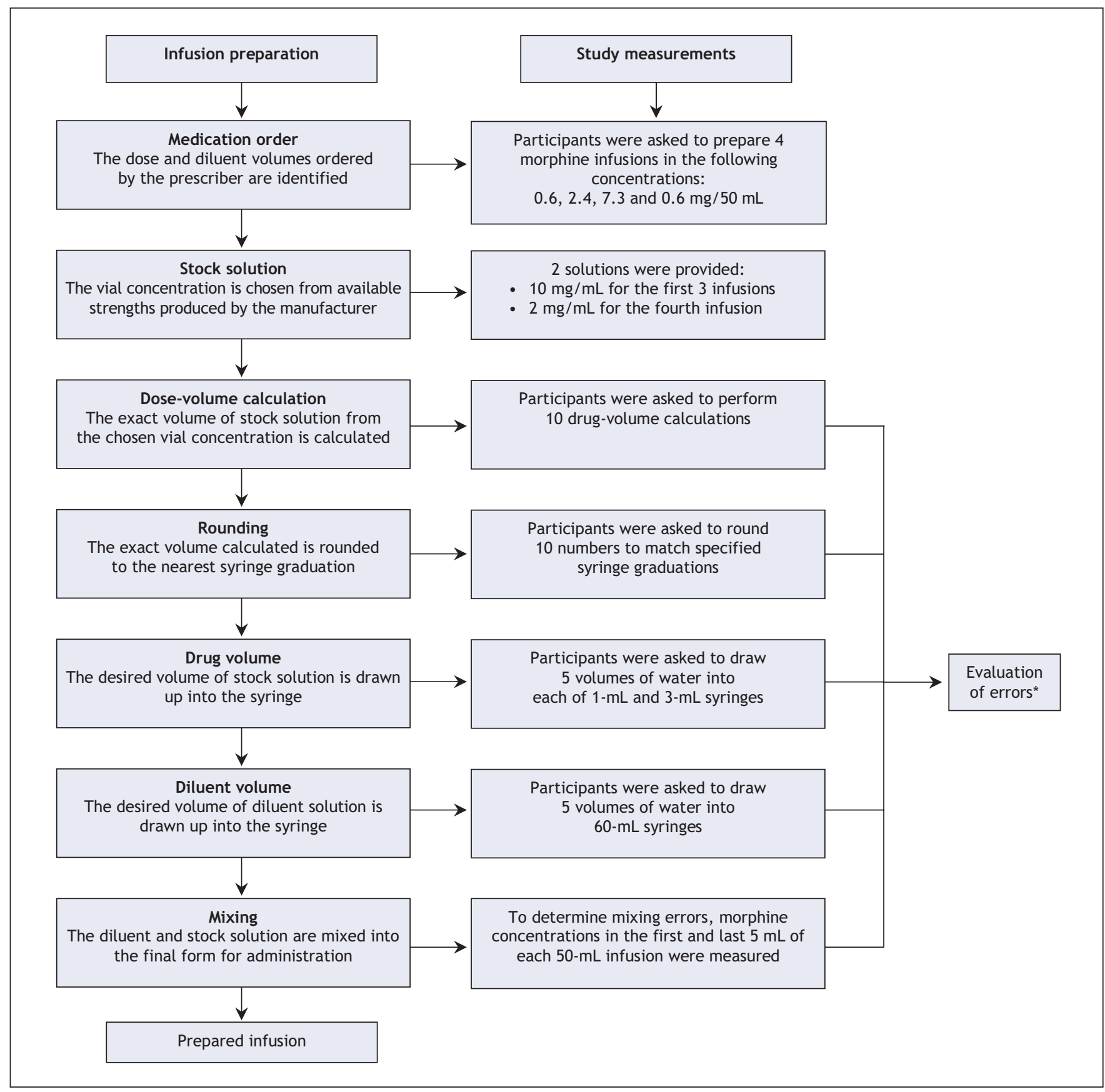

Figure 1: Steps involved in infusion preparation and corresponding tasks required of participants The first 2 steps (medication order and vial concentration) were predetermined as part of the study design. Errors were evaluated in the 5 other tasks. ${ }^{*}$ An error was identified if the result of the task or the concentration of the prepared infusion deviated by $10 \%$ or more from the expected value; a volumetric error was defined as a deviation of $5 \%$ or more from the expected volume; in addition, absolute log-transformed errors were calculated from the worst concentration measured versus the ideal (ordered) concentration. 


\section{Accuracy of prepared morphine infusions}

Overall, I6I (34.7\%, 95\% CI $30.4 \%$ to $39.0 \%$ ) of the morphine infusions had errors. The median percentage error of the 464 prepared infusions was $4.7 \%$ ( $\min$ to $\max ,-89 \%$ to I003\%). There was a greater number of errors among the morphine infusions prepared to a final concentration of $0.6 \mathrm{mg} / 50 \mathrm{~mL}$ from the $10-\mathrm{mg} / \mathrm{mL}$ stock solution than among those prepared from $2-\mathrm{mg} / \mathrm{mL}$ stock solution $(p<0.00 \mathrm{I})$ (Table 3). Participants estimated an error rate of o\%-30\% for the infusions they had prepared (mean $9 \%, n=$ II4). The selfestimated error was rate was $36 \%$ lower than the mean error rate for the 4 infusions prepared by each subject $(p<0.00 I)$.

\section{Factors associated with infusion errors}

The number of morphine infusions prepared by each participant that had a concentration error of Io\% or greater was positively associated with 3 factors: fewer infusions prepared in the previous week ( $p=0.06)$, increased number of years of professional experience $(p=0.04)$ and profession $(p=0.02)$ (Table 2). This model explained $14 \%$ of the observed variation in the number of errors produced by each participant $\left(r^{2}=0.14\right)$.

Repeated-measures analysis of individual infusions identified 4 factors positively associated with the occurrence of a concentration error: fewer infusions prepared in the previous week ( $p=0.007)$, increased number of years of professional experience $(p=0.0 \mathrm{I})$, use of the more concentrated stock solution $(p<0.00 I)$ and preparation of smaller dose volumes $(p<0.00 \mathrm{I})$. There was no significant interaction between variables.

In terms of the magnitude of errors, larger errors in individual infusions were associated with sleeping fewer hours in the 24 hours before the study ( $p=0.02$ ), use of the more concentrated stock solution $(p<0.00 \mathrm{I})$ and preparation of smaller dose volumes $(p<0.00 \mathrm{r})$.

\section{Interpretation}

We performed a direct-observation study of the accuracy of intravenous infusions prepared by health care professionals. We evaluated participants' completion of 5 infusionpreparation tasks and, using an objective laboratory-based assessment, the accuracy of prepared morphine infusions. We found errors in $\mathrm{I} .5 \%-4.9 \%$ of the infusion-preparation tasks and in $34.7 \%$ of the prepared infusions. The frequency of errors detected in our study was half that found using a concealed design, ${ }^{17,18}$ similar to that found in methotrexate infusions administered to children with leukemia ${ }^{32}$ and 5 -times greater than the frequency of medication-order errors. ${ }^{2}$

We found that the errors of the greatest magnitude were made when the morphine infusions were prepared from small volumes of stock solutions. Smaller volumes may be used to prepare solutions from concentrated solutions or to prepare small doses (e.g., for children). This suggests that small children and neonates may be at greater risk than larger patients for these preparation-associated errors. A post-hoc analysis of volume-measurement errors from solutions prepared using I-mL syringes confirmed that smaller volumes were associated with larger errors $(p=0.008)$. However, these volume-measurement errors were small ( $1 \%-2 \%$ ) compared with the magnitude of errors we observed in prepared infusions.

Table 1: Self-reported professional characteristics of 118 health care professionals who completed 5 infusion-preparation tasks and prepared morphine infusions

\begin{tabular}{|c|c|c|c|c|c|}
\hline \multirow[b]{2}{*}{ Characteristic } & \multicolumn{3}{|c|}{ Profession; no. (\%) of participants* } & \multirow[b]{2}{*}{$\begin{array}{l}\text { Overall } \\
n=118\end{array}$} & \multirow[b]{2}{*}{$p$ value $\neq$} \\
\hline & $\begin{array}{c}\text { Anesthesia } \\
n=20\end{array}$ & $\begin{array}{c}\text { Pharmacy } \\
\quad n=17\end{array}$ & $\begin{array}{c}\text { Nursing } \\
n=81\end{array}$ & & \\
\hline $\begin{array}{l}\text { Years of professional } \\
\text { experience§ }\end{array}$ & & & & & 0.12 \\
\hline$<5$ & $3(15)$ & $7(41)$ & $29(36)$ & $39(33)$ & \\
\hline $\begin{array}{l}\text { Infusions prepared in the } \\
\text { previous week } \emptyset\end{array}$ & & & & & $<0.001$ \\
\hline 0 & $5(25)$ & $7(41)$ & $15(19)$ & $27(23)$ & \\
\hline $1-5$ & $10(50)$ & $1 \quad(6)$ & $39(48)$ & $50(42)$ & \\
\hline
\end{tabular}

Note: SD = standard deviation.

*Unless stated otherwise.

†Pharmacy staff included 4 pharmacists and 13 pharmacy technicians.

¥Overall comparison between anesthesia, pharmacy and nursing.

$\S$ Number of years of clinical experience since graduation.

१Does not include infusions prepared for rapid ("push") administration. 
Our findings challenge the dogma that expertise is synonymous with seniority, and they highlight the distinction between recent practice and cumulative experience. We found a greater magnitude of errors in the infusions prepared by participants who reported sleeping fewer hours in the 24 hours before the study, which is consistent with observations of fatigue-associated reductions in performance. ${ }^{33}$

Medication-safety practices may be improved by the follow- ing individual, regulatory and institutional changes. First, the use of electronic calculators by front-line staff is likely to reduce calculation errors. However, this may not significantly reduce preparation errors. Second, the use of dilute stock solutions in the preparation of infusions may improve quality. Third, there may be practical and cost advantages to the centralized preparation of medications. ${ }^{34-36}$ Although our data suggest that this strategy may reduce the number of errors, it would not signifi-

Table 2: Relation between professional characteristics and errors in completing infusion-preparation tasks and preparing morphine infusions among study participants who made at least 1 error

\begin{tabular}{|c|c|c|c|c|c|c|}
\hline \multirow[b]{2}{*}{ Characteristic } & \multirow[b]{2}{*}{$n$} & \multicolumn{5}{|c|}{ Error*; no. (\%) of participants who made at least 1 error } \\
\hline & & $\begin{array}{l}\text { Drug-volume } \\
\text { calculation }\end{array}$ & Rounding $\dagger$ & Volumetric $†$ & Mixing & $\begin{array}{c}\text { Infusion } \\
\text { concentration }\end{array}$ \\
\hline \multicolumn{7}{|l|}{ Profession } \\
\hline Anesthesia & 20 & $9(45)$ & $2(10)$ & $3(15)$ & $2(11)$ & $19(100)$ \\
\hline Pharmacy & 17 & $6(35)$ & $1(6)$ & $4(24)$ & $0 \quad(0)$ & $13(81)$ \\
\hline Nursing & & $p=0.81$ & $p=0.46$ & $p=0.70$ & $p=0.50$ & $p=0.04$ \\
\hline \multicolumn{7}{|c|}{$\begin{array}{l}\text { Years of professional } \\
\text { experience }\end{array}$} \\
\hline$<5$ & 39 & $15(38)$ & $4(10)$ & $5(13)$ & $3(8)$ & $26 \quad(68)$ \\
\hline $6-10$ & 41 & 11 (27) & 2 (5) & 9 (22) & 1 (3) & $35 \quad(90)$ \\
\hline 0 & 27 & 10 (37) & $1 \quad(4)$ & 7 (26) & 1 (4) & $24 \quad(96)$ \\
\hline $1-5$ & 50 & 18 (36) & $9(18)$ & 7 (14) & $5(10)$ & $38 \quad(76)$ \\
\hline $6-10$ & 23 & 11 (48) & $4(17)$ & $3(13)$ & $0 \quad(0)$ & $18 \quad(86)$ \\
\hline \multirow[t]{2}{*}{$>10$} & 18 & 7 (39) & 4 (22) & 3 (17) & 1 (4) & $12 \quad(67)$ \\
\hline & & $p=0.80$ & $p=0.23$ & $p=0.57$ & $p=0.62$ & $p=0.06$ \\
\hline
\end{tabular}

*Calculation, rounding, mixing and infusion-concentration errors were defined as a deviation of $10 \%$ or greater from the expected value. Volumetric errors were defined as a deviation of $5 \%$ or greater from the expected volume. Errors were assessed based on 10 drug-volume calculations, 10 rounding calculations, 12 syringevolumes measurements, 3-4 mixing assessments and 4 morphine-infusion preparations.

†Results from 118 participants were evaluated for calculation, rounding and volumetric errors.

$\ddagger$ Samples were available for 114 participants for analysis of errors in mixing and concentration of infusions.

Table 3: Errors* detected in morphine infusions prepared by 118 health care professionals

\begin{tabular}{|c|c|c|c|c|}
\hline $\begin{array}{l}\text { Required concentration, } \\
\mathrm{mg} / 50 \mathrm{~mL}\end{array}$ & $\begin{array}{l}\text { Final volume, } \\
\text { mL }\end{array}$ & $\begin{array}{c}\text { Samples } \\
\text { analyzed, no. }\end{array}$ & \multicolumn{2}{|c|}{ Magnitude of error; no. (\%) $\dagger$ of errors } \\
\hline 0.6 & 0.06 & 116 & $70(60)$ & $31(27)$ \\
\hline 2.4 & 0.24 & 116 & $17(15)$ & 1 (1) \\
\hline $0.6 \mathrm{mg}$ & 0.3 & 116 & $36(31)$ & $3 \quad(3)$ \\
\hline Overall & & 464 & $161(35)$ & $36 \quad(8)$ \\
\hline
\end{tabular}

*Errors were directly measured by use of high-performance liquid chromatography.

†Percentages calculated across rows. 
cantly reduce errors of larger magnitude (Table 2). Remote preparation of medications may not be ideal, because delays in the availability of medications may result in adverse outcomes. ${ }^{37}$ Fourth, methods that reduce or better manage fatigue may improve technical performance..$^{12,33,38-40}$ Fifth, the use of standardized infusion concentrations may reduce errors if the concentrations selected are matched to appropriately dilute stock concentrations. Indeed, the Joint Commission for the Accreditation of Health Care Organizations has recommended the use of standardized infusion concentrations. ${ }^{8}$ However, even in the best case, we found errors in $15 \%$ of infusions (Table 3). Finally, the use of pre-filled syringes ${ }^{41}$ or ready-mixed infusions prepared to industry standards ${ }^{22,42}$ would improve the accuracy of medication dosing and may better serve the therapeutic needs of children. ${ }^{43}$ However, this may result in a new set of errors related to the use of infusion rates to determine dosing with fixed concentrations and may complicate fluid management in critically ill children.

Our study has several limitations. Previous studies that used concealed direct observation reported that up to $65 \%$ of medication infusions contained errors. ${ }^{17,18}$ This suggests that our finding of a $35 \%$ error rate is probably a conservative estimate and that our finding may be of limited generalizability to clinical practice. The participants in our study may not have been representative of the population of practitioners in other more general practices. In addition, they may have altered their performance because they knew they were being observed, because they were in a nonclinical environment, because there was no second health care professional available to check their preparation or because of the artificial simplification of the preparation process (in order to permit evaluation) ${ }^{44,45}$ Nevertheless, our data provide an integrated and objective evaluation of multiple aspects of the medicationpreparation process. Measurable factors explained only $\mathrm{I} 4 \%$ of the variation in the number of morphine infusions with a concentration error. We may not have measured other important variables, or we may have used an inappropriate analytical model. Our results reflect the greater complexity of the integrated preparation task versus isolated infusionpreparation tasks. We did not identify any simple correctable factors in the current process of infusion preparation that could prevent preparation-associated errors. We believe that exploring alternative methods of preparation, specifically alternative concentrations of stock solutions and the use of industry-prepared infusions, warrants further clinical and economic evaluation.

\section{Conclusion}

We found that more than one-third of infusions prepared by health care professionals in our study had concentrations outside the accepted pharmaceutical standards. The causes of these errors were multifactorial and included experience, professional background and fatigue. The main contributing factor was the use of the more concentrated stock solution to prepare smaller (pediatric) doses.

Evaluation of the clinical and economic impact of stock solutions suitable for pediatric patients and industry-prepared infusions is required. Preparation of medicine at doses appropriate for use in children has the potential to reduce preventable errors and to improve clinical care and patient outcomes.

This article has been peer reviewed.

Competing interests: None declared.

Contributors: Christopher Parshuram drafted the manuscript. All of the authors participated in the study design, the analysis and interpretation of the data, and the critical revision of the manuscript. All of the authors approved the final version submitted for publication.

Acknowledgements: We thank the following people for their assistance: Derek Stephens and Mohamed Abodell (study design); Lisa Mak and Karen Bushe (participant enrolment); Lisa Mak, Karen Bushe, Rachael Patel and Elaine Meertens (data collection); Lisa Mak, Karen Bushe and Serghei Gargiun (data entry); Scott Walker (laboratory assay); Olga Vasilyeva (data analysis); and Ross Baker (interpretation of data).

This study was funded by a Patient Safety Grant from the Society of Critical Care Medicine. Christopher Parshuram is a Career Scientist of the Ontario Ministry of Health and Long-Term Care.

\section{REFERENCES}

I. Bates DW, Boyle D, Vander VM, et al. Relationship between medication errors and adverse drug events. J Gen Intern Med I995;I0:199-205.

2. Kaushal R, Bates DW, Landrigan C, et al. Medication errors and adverse drug events in pediatric inpatients. JAMA 2001;285:2114-20.

3. Landrigan CP, Rothschild JM, Cronin JW, et al. Effect of reducing interns' work hours on serious medical errors in intensive care units. $N$ Engl J Med 2004;35I: I838-48.

4. Baker GR, Norton PG, Flintoft V, et al. The Canadian Adverse Events Study: the incidence of adverse events among hospital patients in Canada. CMAJ 2004;170: I678-86.

5. Leape LL, Brennan TA, Laird N, et al. The nature of adverse events in hospitalized patients. Results of the Harvard Medical Practice Study II. N Engl J Med I991;324: 377-84.

6. Thomas EJ, Studdert DM, Burstin HR, et al. Incidence and types of adverse events and negligent care in Utah and Colorado. Med Care 2000;38:26I-7I.

7. Wilson RM, Runciman WB, Gibberd RW, et al. The Quality in Australian Health Care Study. Med J Aust I995;I63:458-7I.

8. The Joint Commission. National patient safety goals, 2004. Oakbrook Terrace (IL): The Commission: 2004. Available: www.jointcommission.org/PatientSafety/National PatientSafetyGoals/2004_npsgs.htm (accessed 2007 Nov 12).

9. Evidence-based Practice Center, University of California at San Francisco. Making health care safer: a critical analysis of patient safety practices. San Francisco: The Center; 200I. Available: http://biotech.law.lsu.edu/policy/ptsafety.pdf (accessed 2007 Oct I8).

Io. National Quality Forum. Safe practices for better health care. Washington: The Forum; 2003. Available: www.qualityforum.org/pdf/reports/safe_practices.pdf (accessed 2007 Nov 26)

II. Hannan EL, Racz M, Kavey RE, et al. Pediatric cardiac surgery: the effect of hospital and surgeon volume on in-hospital mortality. Pediatrics I998; I0I:963-9.

I2. Gaba DM, Howard SK. Patient safety: fatigue among clinicians and the safety of patients. NEngl J Med 2002;347:1249-55.

I3. Philibert I. Sleep loss and performance in residents and nonphysicians: a meta-analytic examination. Sleep 2005;28:1392-402.

I4. United States Pharmacopeia Convention. United States Pharmacopeia (27th edition). Rockville (MD): The Convention; I999.

I5. British Pharmacopoeia Commission. British Pharmacopoeia 2006. London (UK): The Stationary Office; 2006

I6. Parshuram CS, Dupuis LL, To T, et al. Occurrence and impact of unanticipated variation in intravenous methotrexate dosing. Ann Pharmacother 2006;40:805-II.

I7. Parshuram CS, Ng GY, Ho TK, et al. Discrepancies between ordered and delivered concentrations of opiate infusions in critical care. Crit Care Med 2003;31:2483-7.

I8. Ferner RE, Langford NJ, Anton C, et al. Random and systematic medication errors in routine clinical practice: a multicentre study of infusions, using acetylcysteine as an example. BrJ Clin Pharmacol 2001;52:573-7.

I9. Allen EM, Van Boerum DH, Olsen AF, et al. Difference between the measured and ordered dose of catecholamine infusions. Ann Pharmacother 1995;29:1095-Io0.

20. Allen-Webb EM, Ross MP, Pappas JB, et al. Age-related amrinone pharmacokinetics in a pediatric population. Crit Care Med I994;22:1016-24.

2I. Bell DS, Clements RS, Perentesis G, et al. Dosage accuracy of self-mixed vs premixed insulin. Arch Intern Med I991;151:2265-9.

22. Dasta JF, Bonfiglio MF, Rague NG, et al. Accuracy and variability of intravenous theophylline preparations. Ther Drug Monit I990;12:554-7.

23. Sanders LH, Mabadeje SA, Avis KE, et al. Evaluation of compounding accuracy and aseptic techniques for intravenous admixtures. Am J Hosp Pharm I978;35:531-6. 
24. Rowe C, Koren T, Koren G. Errors by paediatric residents in calculating drug doses. Arch Dis Child i998;79:56-8.

25. Nahata MC, Morosco RS, Hipple TF. Stability of morphine sulfate in bacteriostatic $0.9 \%$ sodium chloride injection stored at two temperatures. Am J Hosp Pharm I992;49:2785-6.

26. Walker SE, Coons C, Matte D, et al. Hydromorphone and morphine stability in portable infusion pump cassettes and minibags. Can J Hosp Pharm I988;41:177-82.

27. Hor MM, Chan SY, Yow KL, et al. Stability of morphine sulphate in saline under simulated patient administration conditions. J Clin Pharm Ther I997; 22: 405-Io.

28. Vecchio M, Walker SE, Iazzetta J, et al. Stability of morphine intravenous infusion solutions. Can J Hosp Pharm I988;4I:5-9.

29. Sackett D, Haynes RB, Tugwell P, et al. Clinical epidemiology: a basic science for clinical medicine. Boston: Little Brown; I99I.

30. International Organization for Standardization. Sterile hypodermic syringes for single use. Part I: Syringes for manual use (ISO 7886-I:I993). Available: www.iso.org /iso/iso_catalogue/catalogue_tc/catalogue_detail.htm?csnumber $=14835$ (accessed 2007 Oct I8).

31. International Organization for Standardization. Sterile hypodermic syringes for single use. Part 2: Syringes for use with power-driven syringe pumps (ISO 7886-2: I996). Available: www.iso.org/iso/iso_catalogue/catalogue_tc/catalogue _detail.htm?csnumber=2I0I7 (accessed 2007 Oct I7).

32. Parshuram CS, Kirpalani H, Mehta S, et al. In-house, overnight physician staffing: a cross-sectional survey of Canadian adult and pediatric intensive care units. Crit Care Med 2006;34:1674-8.

33. Dawson D, Reid K. Fatigue, alcohol and performance impairment. Nature 1997; 388:235.

34. Fraind DB, Slagle JM, Tubbesing VA, et al. Reengineering intravenous drug and fluid administration processes in the operating room: step one: task analysis of existing processes. Anesthesiology 2002;97:139-47

35. Armour DJ, Cairns CJ, Costello I, et al. The economics of a pharmacy-based central intravenous additive service for paediatric patients. Pharmacoeconomics ig96; Io: 386-94.
36. Chan R, Ryan M, Moriarty S, et al. The impact of centralized reconstitution of intravenous additives service on administration times of intravenous antibiotics. Eur J Hosp Pharm 1993;3:93-5.

37. Han YY, Carcillo JA, Venkataraman ST, et al. Unexpected increased mortality after implementation of a commercially sold computerized physician order entry system. Pediatrics 2005;II6:I506-I2.

38. Aya AG, Mangin R, Robert C, et al. Increased risk of unintentional dural puncture in night-time obstetric epidural anesthesia. Can J Anaesth I999;46:665-9.

39. Taffinder NJ, McManus IC, Gul Y, et al. Effect of sleep deprivation on surgeons' dexterity on laparoscopy simulator. Lancet I998;352:II9I.

40. Dawson D, McCulloch K. Managing fatigue: It's about sleep. Sleep Med Rev 2005; 9:365-80.

4I. Webster CS, Merry AF, Gander PH, et al. A prospective, randomized clinical evaluation of a new safety-orientated injectable drug administration system in comparison with conventional methods. Anaesthesia 2004;59:80-7.

42. Manasse HR. Toward defining and applying a higher standard of quality for medication use in the United States. Am J Health Syst Pharm 1995;52:374-9.

43. Shirkey H. Therapeutic orphans. Pediatrics I999;I04:583-4.

44. Barker KN. Data collection techniques: observation. Am J Hosp Pharm 1980;37: I235-43.

45. Flynn EA, Barker KN, Gibson JT, et al. Impact of interruptions and distractions on dispensing errors in an ambulatory care pharmacy. Am J Health Syst Pharm 1999; 56:1319-25.

Correspondence to: Dr. Christopher S. Parshuram, Department of Critical Care Medicine, Hospital for Sick Children, 555 University Ave., Toronto ON M5G IX8; fax 4 I6 8I3-7299;

christopher.parshuram@sickkids.ca

\section{How you can get involved in the CMA!}

The CMA is committed to providing leadership for physicians and promoting the highest standard of health and health care for Canadians. To strengthen the Association and be truly representative of all Canadian physicians, the CMA needs to hear from members interested in serving in elected positions and on appointed committees and advisory groups.

The CMA structure comprises both governing bodies and advisory bodies either elected by General Council or appointed by the CMA Board of Directors. The Board of Directors - elected by General Council — has divisional, affiliate, resident and student representation, is responsible for the overall operation of the CMA and reports to General Council on issues of governance. CMA councils and committees advise the Board of Directors and make recommendations on specific issues of concern to physicians and the public. Five core councils and committees consist of either divisional or regional representation, while other statutory and special committees, and task forces consist of individuals with interest and expertise in subject-specific fields. Positions on one or more of these committees may become available in the coming year.

For further information on how you can get involved, please contact:

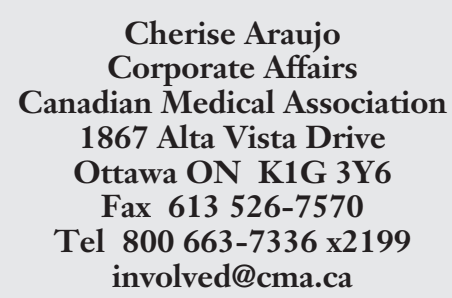

By getting involved, you will have an opportunity to make a difference.

We hope to hear from you!

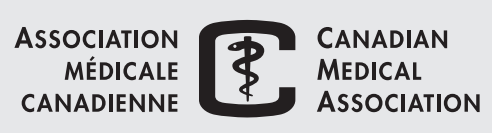

